\title{
Desain Selubung Bangunan Untuk Bangunan Hemat Energi
}

\author{
M.Y.Noorwahyu Budhyowati ${ }^{1}$, Djubir R.E. Kembuan ${ }^{2}$ \\ Program Studi Arsitektur, Fakultas Teknik, Universitas Negeri Manado \\ Tondano, Indonesia \\ Email : mynoorwahyub@yahoo.com
}

\begin{abstract}
Abstrak
Tulisan ini menjelaskan cara merancang selubung bangunan dan acuan yang dapat digunakan untuk merancang bangunan hemat energi. Merupakan penelitian kuantitatif, menggunakan analisis matematis, fokus pembahasan pada Desain Konstruksi Dinding. Diharapkan dapat membantu mengoptimalkan desain selubung bangunan yang memiliki nilai transmitan yang kecil, guna mengurangi beban panas dalam bangunan.

Penelitian dilakukan dengan mencari nilai konduktivitas untuk mengetahui besar pengaliran panas material, ketebalan bahan yang mempengaruhi nilai resistan, menghitung nilai resistan dan transmitan keseluruhan perpaduan bahan pada desain. Hasil penelitian menunjukkan bahwa merancang bangunan hemat energi harus memperhatikan desain selubung bangunannya. Pengurangan beban panas dalam bangunan dapat dilakukan dengan cara penggunaan desain dinding dengan nilai transmitan yang kecil. Pemilihan bahan, perpaduan beberapa jenis bahan dan desain yang tepat dapat menghasilkan bangunan hemat energi. Pada penelitian, dibuat Tabel Perhitungan Nilai Transmitan, sehingga data yang dimasukkan adalah detail desain konstruksi dinding yang diinginkan yaitu ketebalan, nilai konduktivitas material, nilai resistan udara permukaaan luar dan udara permukaaan dalam, sehingga didapat nilai resistan dari masing-masing bahan, nilai total resistan, dan nilai transmitan dari desain konstruksi yang diinginkan.

Untuk menyempurnyakan penelitian ini dibutuhkan adanya penelitian lanjutan tentang selubung bangunan hemat energi yang difokuskan pada desain konstruksi atap bangunan.
\end{abstract}

Kata kunci : bangunan hemat energi, desain konstruksi dinding, nilai transmitan

Abtract

This paper describes how to design building envelopes and references that can be used to design energy-efficient buildings. This is a quantitative research, using mathematical analysis, focusing on the discussion on Wall Construction Design. It is hoped that it can help optimize the design of the building envelope which has a small transmittance value, in order to reduce the heat load in the building. The research was conducted by looking for the conductivity value to determine the amount of heat flow of the material, the thickness of the material that affects the resistance value, calculating the value of resistance and transmittance of the overall blend of materials in the design. The results of the study indicate that designing an energy-efficient building must pay attention to the design of the building envelope. Reduction of heat load in the building can be done by using a wall design with a small transmittance value. Selection of materials, a combination of several types of materials and right design can produce energyefficient buildings. In the study, a transmittance value calculation table was made, so it was only necessary to enter the desired wall construction design details, namely the thickness, the 
conductivity value of the material, the resistance value of the outer surface air and the inner surface air, so that the resistance value of each material was obtained, the total resistance value, and transmittance value of the desired construction design.

To complete this research, further research is needed on energy-efficient building envelopes that are focused on the design of building roof construction.

Keywords: energy-efficient building, wall construction design, transmittance value

\section{PENDAHULUAN}

Letak geografis Indonesia yang berada di daerah tropis lembab menyebabkan iklim Indonesia secara termal tidak comfortable. Untuk mengatasi masalah ketidaknyamanan termal, digunakan mesin pengkondisian udara (Air Conditioning atau AC) yang dapat membuat suhu ruangan menjadi nyaman sesuai dengan kebutuhan kenyamanan termal tubuh. Penggunaan AC memang memberi banyak keuntungan, namun kekurangannya terutama pada penggunaan energi yang boros (Satwiko, 2009).

Pembatasan penggunaan energi di Indonesia saat ini dilakukan dengan cara pengawasan terhadap desain bangunan yang harus mengikuti standar Green Building oleh Green Building Council Indonesia (GBCI) yang salah satunya adalah berkewajiban untuk membuat desain bangunan yang hemat energi, dengan kepatuhan terhadap SNI yang saat ini masih berlaku yaitu SNI 03-6572-2001, dan akan direvisi RSNI 6389-2020 yang sedang dibahas.

Kepatuhan terhadap SNI ini dibuktikan dengan melakukan perhitungan Overall Thermal Transfer Value (OTTV) dan Roof Thermal Transfer Value (RTTV) dimana setiap bangunan wajib melakukan perhitungan nilai OTTV dan RTTV untuk selubung bangunannya dengan memasukkan semua permukaan selubung bangunan baik vertikal (dinding), horizontal (atap), baik permukaan yang transparan dan tidak transparan, sedangkan perhitungan nilai ini sangat berhubungan dengan besar kecilnya nilai perpindahan panas (Transmitan, U-Value) dari selubung bangunan. Kriteria OTTV dan RTTV yang ditentukan saat ini tidak boleh melebihi $35 \mathrm{~W} / \mathrm{m}^{2}$ (SNI 6389:2011), untuk mencapai ketentuan tersebut sangat tidak mudah, sehingga mau tidak mau Arsitek harus secermat mungkin membuat desain selubung bangunan yang dapat menahan panas sehingga nilai perpindahan panas ke dalam bangunan menjadi kecil dan bangunan menjadi hemat energi (ASHRAE.2001).

Dalam penelitian ini dirumuskan masalah yaitu bagaimana cara merancang selubung bangunan yang baik untuk bangunan hemat energi dan apakah sudah ada acuan yang dapat digunakan untuk merancang bangunan hemat energi, tujuan penelitian untuk mengetahui cara merancang selubung bangunan yang baik untuk bangunan hemat energi dan mendapat acuan untuk memudahkan dalam merancang bangunan hemat energi yang bermanfaat membantu merancang bangunan dengan mengoptimalkan desain selubung bangunan yang memiliki nilai perpindahan panas atau nilai transmitan (U-Value) yang kecil guna mengurangi beban panas dalam bangunan. Penelitian ini merupakan inovasi dalam bidang ilmu Teknik Aritektur dalam rekayasa desain selubung bangunan yang sangat dibutuhkan dalam perancangan bangunan hemat energi saat ini. Untuk lebih fokus dalam pembahasan, penelitian ini dibatasai pada desain selubung bangunan dengan fokus analisis pada desain dinding bangunan dan perhitungan nilai perpindahan panas melalui tiap jenis desain selubung bangunan.

\section{TINJAUAN PUSTAKA}

\subsection{Beban Penyejukan ( Cooling Load )}

Proses penyejukan pada mesin AC intinya adalah udara panas di dalam ruangan dihisap kemudian diolah menggunakan komponen-komponen AC dan akhirnya dikeluarkan menjadi udara dingin. Udara panas yang dihisap inilah yang menjadi beban penyejukan pada AC yang

Jurnal Teknik Sipil Terapan (JTST), e-ISSN 2714-7843 
harus dibuang oleh AC dari dalam ruang keluar ruang agar suhu udara di dalam ruang tidak naik dan tetap dalam batas kenyamanan termal yang dikehendaki (Arismunandar,1995). Semakin panas suhu dalam ruangan menyebabkan kerja mesin AC menjadi semakin berat, hal ini menyebabkan penggunaan energi listrik yang besar. Beban penyejukan terbagi 2 yaitu :

1. Beban penyejukan luar (external cooling load) yang masuk melalui :

a. Selubung bangunan

b. Partisi

c. Ventilasi dan infiltrasi

2. Beban penyejukan dalam (internal cooling load).

a. Manusia (people)

b. Penerangan (lighting)

c. Peralatan (equipment)

\subsection{Selubung Bangunan (Building Envelope )}

Selubung bangunan terdiri dari komponen tak tembus cahaya ( dinding) dan sistem fenestrasi atau komponen tembus cahaya (jendela) yang memisahkan interior bangunan dari lingkungan luar (Lovell 2010) Pada bangunan gedung bertingkat menengah dan tinggi, luas dinding jauh lebih besar daripada luas atap, oleh karena itu perancangan selubung bangunan vertikal harus dilakukan secara hati-hati pada desain dinding bangunan untuk menghindari masuknya panas berlebih ke dalam bangunan, sedangkan untuk bangunan bertingkat rendah, atap menjadi bagian yang lebih luas daripada dinding sehingga atap memungkinkan menjadi penentu beban panas yang masuk ke dalam bangunan ( Mediastika Ch.2013).

\subsection{Bangunan Hemat Energi}

1. Proses Desain Terintegrasi (Integrated Design Process)

Mencakupi karakteristik lokasi dan desain bangunan, yang meliputi pilihan-pilihan arsitektur, struktural, mekanik, dan listrik dengan tujuan untuk meminimalisasi konsumsi energi.

2. Pilihan Material dan Teknologi.

Seluruh material dan teknologi yang digunakan pada muka dari lapisan luar dari selubung bangunan harus tepat sehingga dapat mengurangi panas masuk ke dalam bangunan.

3. Iklim

Karena kebanyakan energi dalam bangunan digunakan untuk memastikan kenyamanan manusia, jelas bahwa iklim sekeliling serta kondisi dari dalam ruangan yang ditargetkan memiliki dampak yang besar bagi kinerja energi bangunan.

4. Pertimbangan Estetika

Tantangan terbesar dalam meningkatkan efisiensi energi pada bangunan umum dan komersial adalah membangun arsitektur yang memuaskan secara estetika dan pada saat yang bersamaan memenuhi syarat teknis yang ditentukan oleh iklim lokal dan pilihan material yang tersedia.

\subsection{Beban Selubung Bangunan}

Upaya dalam menyiapkan desain dan proses konstruksi yang hemat energi maka perlu diketahui dan memahami elemen-elemen utama efisiensi energi (Dewan Energi Nasional Republik Indonesia. 2014),

a. Beban penyejukan yang berasal dari luar melalui selubung bangunan, misalnya untuk gedung kantor satu lantai di Indonesia dapat mencapai 40\% sampai 50\% dari beban pendingin seluruhnya pada waktu terjadi beban puncak.

b. Agar gedung yang direncanakan dapat memenuhi persyaratan hemat energi, maka pada awal perencanaan perlu dihitung besarnya nilai perpindahan termal menyeluruh Overall Thermal Transfer Value (OTTV) dan Roof Thermal Transfer Value (RTTV) dan dibandingkan terhadap batas yang ditentukan dalam standar yang berlaku. 
c. Apabila nilai yang diperoleh melampaui batas yang ditentukan bagi gedung hemat energi, maka perlu dilakukan perubahan perencanaan Arsitektur agar diperoleh nilai yang memenuhi ketentuan untuk gedung hemat energi.

Adapun panas dialirkan ke dalam bangunan melalui tiga cara, yaitu konduksi, konveksi, dan radiasi. Aliran Panas (heat transfer) didefinisikan sebagai perpindahan energi antara dua daerah karena perbedaan suhu (Bradshaw, 1993).

\subsection{Transmitan (Transmitance,U-Value) dan Perhitungan panas yang masuk dalam bangunan}

Bahan bangunan turut menentukan nilai transmitansi termal, kesalahan dalam menentukan transmitansi termal dapat menimbulkan kesalahan dalam perhitungan beban penyejukan. Identifikasi bahan bangunan serta memperkirakan nilai transmistansi termalnya perlu dilakukan dengan cermat dan hati-hati (SNI 03-6390-2011). Sifat bahan (material properties) adalah sifat fisik khas suatu bahan sehingga pemilihan dan penerapannya harus selektif dan tepat ( Prakoso,dkk.2014) . Beberapa sifat bahan yang relevan dalam perpindahan panas (Frick,dkk. 2008) yaitu Konduktivitas (conductivity) dan Resistivitas (resistivity) adalah kebalikan dari konduktivitas,sedangkan dalam perhitungan daya tahan terhadap panas, ketahanan termal disebut resistan (Resistance, R). Komponen bahan bangunan yang terdiri dari beberapa jenis bahan, maka nilai $\mathrm{R}$ diperoleh dengan menjumlah $\mathrm{R}$ dari masing-masing bahan. Besarnya perpindahan panas dari suatu komponen yang terdiri atas beberapa jenis bahan bangunan adalah kebalikan dari nilai $\mathrm{R}$ dari komponen bangunan. Angka konduktan elemen bangunan yang sudah memasukkan faktor konduktan permukaan disebut transmitan (U-Value).

\section{METODE PENELITIAN}

\subsection{Rancangan Penelitian}

Penelitian ini merupakan penelitian kuantitatif dengan menggunakan analisis matematis. Fokus penelitian pada Desain Dinding bangunan

Sebagaimana yang diuraikan dalam Bab 1 Pendahuluan, terdapat rumusan masalah yang terkait dengan kendala-kendala yang dialami oleh para Perencana dalam mendesain selubung bangunan yang hemat energi, dan kurangnya acuan yang dapat digunakan, oleh karena itu untuk mencapai tujuan yang diharapkan maka penelitian dilakukan dengan tahapan:

- Tahap 1 : Pada tahap ini dilakukan studi literatur yang mencakup semua yang berhubungan dengan sifat-sifat pengaliran panas pada material dan hasil-hasil penelitian terdahulu. Tujuan studi literatur adalah membangun kerangka teori tentang kendala dalam mendesain selubung bangunan yang efektif dan efisien pada bangunan gedung dengan fungsi dan manfaat serta biaya yang optimal.

- Tahap 2 : Pada tahap ini dilakukan pengumpulan data tentang material dan dilakukan analisa untuk membuat desain tipe konstruksi selubung bangunan yang memiliki nilai perpindahan panas yang kecil, dan dilakukan penggambaran-penggambaran desain selubung bangunan..

- Tahap 3: Pada tahap ini merampungkan penulisan Laporan Akhir Penelitian dan juga akan menyelesaikan penulisan salah satu luaran penelitian, yaitu publikasi pada Jurnal Nasional

\subsection{Hipotesis}

Selubung bangunan memiliki andil yang besar dalam menentukan penggunaan energi dalam bangunan, terutama dalam penggunaan energi listrik pada mesin pengkondisian udara. Hal ini ditentukan oleh desain selubung bangunannya, dimana desain selubung bangunan yang memiliki nilai perpindahan panas yang kecil dapat mengurangi beban panas dalam bangunan sehingga bangunan menjadi lebih dingin sehingga hemat energi. 


\subsection{Pengumpulan Data}

Pengumpulan data diawali dengan identifikasi terhadap data-data yang dibutuhkan dalam proses penelitian. Data yang digunakan dibagi atas dua yaitu data primer dan data sekunder.

1. Pengumpulan Data Primer

Data primer yaitu data utama yang digunakan dalam proses analisis. Pengumpulan sbb:

1) Studi Literatur

Studi literatur untuk mendapatkan dasar-dasar teori yang digunakan dalam melakukan analisis. Data-data diperoleh dari buku-buku teks, jurnal, standar, juga data lain dari internet.

2) Data Material

Sifat-sifat material yang ada, nilai Konduktivitas, nilai Resistan, ketebalan, dan lain-lain.

2. Pengumpulan Data Sekunder

Data-data yang digunakan sebagai standar dan pedoman dalam analisis. Data ini berupa peraturan-peraturan dari instansi terkait, dan penelitian sebelumnya. yaitu :

1) Badan Standarisasi Nasional. 2001. Tentang Tata Cara Perancangan Sistem Ventilasi Dan Pengkondisian Udara Pada Bangunan Gedung

2) Badan Standarisasi Nasional. 2011. Tentang Konservasi Energi Selubung Bangunan pada Bangunan Gedung

3) Kementerian Energi dan Sumber Daya Mineral. 2012. Tentang Pedoman Energi Efisiensi untuk Desain Bangunan Gedung Indonesia

4) Panduan Pengguna Bangunan Gedung Hijau Jakarta

5) Peraturan Menteri PU dan Perumahan Rakyat no.2/PRT/M/015 tentang Bangunan Gedung Hijau.

6) Penelitian-penelitian sebelumnya yang berkaitan dengan penelitian yang dilakukan.

\subsection{Peralatan dan Pengukuran}

1. Seperangkat komputer dengan program-program yang digunakan untuk pengolahan data dan analisis yaitu program MS Excel, program MS Word, dan program Auto CAD untuk penggambaran.

2. Pengukuran Matematis

a. Perhitungan nilai transmitan $\left(\mathrm{W} / \mathrm{m}^{2} \mathrm{~K}\right)$

Dihitung dengan persamaan : $\mathrm{U}=1 /$ nilai $\mathrm{R}$

b. Absorbsi permukaan bidang yang dicat.

Nilai absorbsi ditentukan oleh material dan warna cat permukaan, dihitung dengan persamaan $\alpha_{\text {total }}=\alpha_{\text {dinding }} \mathrm{x} \alpha_{\text {cat }}$

c. Satwiko, 2009 (nilai $\alpha$, nilai k, panas yang dikeluarkan karena aktivitas manusia, konduktan lapisan udara luar $\left(\mathrm{f}_{\mathrm{o}}\right)$ ).

d. Perhitungan panas melalui dinding dan panas melalui kaca:

$\mathrm{Qc}=\mathrm{A}_{\text {dinding }} \cdot \mathrm{U}_{\text {dinding }} \cdot \Delta \mathrm{T}_{\text {dinding }}+\mathrm{A}_{\text {kaca }} \cdot \mathrm{U}_{\text {kaca }} \cdot \Delta \mathrm{T}_{\text {kaca }}$

e. Perhitungan panas dalam bangunan $\mathrm{Q}_{\mathrm{m}}=\mathrm{Q}_{\mathrm{i}}+\mathrm{Q}_{\mathrm{s}}+\mathrm{Q}_{\mathrm{c}}+\mathrm{Q}_{\mathrm{v}}$

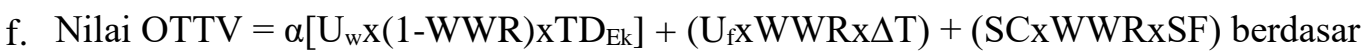
SNI 6389:2011

\section{HASIL DAN PEMBAHASAN}

Bangunan hemat energi adalah bangunan yang memungkinkan penggunaan energi seminimal mungkin tanpa mengurangi produktivitas fungsi bangunan yang ada (Palm, 2010). Untuk itu sangat dibutuhkan pengetahuan tentang perpindahan panas melalui selubung bangunan. Penghematan energi pada penggunaan AC tergantung pada besar kecilnya beban panas yang harus dikeluarkan oleh $\mathrm{AC}$, sedangkan besar kecilnya panas dalam ruangan sangat tergantung pada besarnya panas dari luar yang dipindahkan kedalam ruang melalui selubung 
bangunan ( Sala M.1998). Suhu dalam bangunan tergantung pada suhu luar bangunan. Apabila suhu luar panas, maka suhu dalam ruang pun cenderung akan menjadi panas. Hal ini disebabkan karena adanya perpindahan panas dari luar ruangan ke dalam ruangan melalui komponen pembatas ruang baik terjadi secara radiasi, konduksi, dan konveksi (Bradshaw.1993) . Perpindahan panas yang akan dibahas disini adalah perpindahan secara konduksi melalui komponen dinding bangunan yang merupakan pembatas ruang dimana besarnya perpindahan panas tergantung pada konduktivitas dari bahan komponen pembatas.

Konduktivitas bahan komponen pembatas yang besar dapat mengalirkan panas yang besar, sebaliknya jika konduktivitas bahannya kecil maka panas yang dialirkan pun kecil. Konduktivitas yang besar menyebabkan nilai resistan suatu bahan menjadi kecil, apalagi bila ketebalan suatu bahan tipis. Resistan (R) adalah perbandingan antara ketebalan (d) dan konduktivitas (k). Sebaliknya bila konduktivitas kecil maka resistannya menjadi besar. Jika nilai resistan bahan komponen pembatas besar maka nilai transmitannya (U-Value) menjadi kecil (Szokolay.1980). Mengurangi perpindahan panas dari luar ke dalam bangunan dapat dilakukan dengan mengupayakan nilai transmitan bahan komponen pembatas ruang yang sekecil-kecilnya.

Tabel 1. Nilai Konduktivitas dan Resistan dari material dasar dinding

\begin{tabular}{|c|l|c|c|c|}
\hline \multirow{2}{*}{ NO } & Bahan Dasar Dinding & Ketebalan (d) & Konduktivitas (k) & Resistan (R) \\
\cline { 3 - 5 } & & $\mathbf{m}$ & $\mathbf{W} / \mathbf{m K}$ & $\mathbf{m}^{\mathbf{2}} \mathbf{K} / \mathbf{W}$ \\
\hline $\mathbf{1}$ & Panel Polystyrene $12 \mathrm{~cm}$ & 0,120 & 0,039 & 3,077 \\
\hline $\mathbf{2}$ & Bata Ringan $20 \mathrm{~cm}$ & 0,200 & 0,530 & 0,377 \\
\hline $\mathbf{3}$ & Batako Padat $15 \mathrm{~cm}$ & 0,150 & 0,720 & 0,208 \\
\hline $\mathbf{4}$ & Batu Bata Merah $10 \mathrm{~cm}$ & 0,100 & 0,890 & 0,112 \\
\hline $\mathbf{5}$ & Batako Berlubang $10 \mathrm{~cm}$ & 0,100 & 1,110 & 0,090 \\
\hline 6 & Kayu $1,3 \mathrm{~cm}$ & 0,130 & 0,150 & 0,867 \\
\hline $\mathbf{7}$ & Kayu $3 \mathrm{~cm}$ & 0,030 & 0,150 & 0,003 \\
\hline $\mathbf{8}$ & Kaca Bening $3 \mathrm{~mm}$ & 0,003 & 0,900 & 0,006 \\
\hline $\mathbf{9}$ & Kaca Bening $5 \mathrm{~mm}$ & 0,005 & 0,900 & 0,011 \\
\hline 10 & Kaca Bening $8 \mathrm{~mm}$ & 0,008 & 0,750 & 0,005 \\
\hline 11 & Kaca Warna $3 \mathrm{~mm}$ & 0,003 & 0,630 & 0,014 \\
\hline 12 & Kaca Warna $6 \mathrm{~mm}$ & 0,006 & 0,430 & \\
\hline
\end{tabular}

Sumber : Hasil olahan Peneliti

Pemilihan bahan dan desain selubung yang sesuai, membantu membuat ruangan menjadi dingin. Perpaduan beberapa jenis bahan yang sesuai dan tepat menghasilkan bangunan yang sejuk. Untuk memudahkan penghitungan Nilai Transmitan maka dibuat tabel untuk perhitungan nilai transmitan sehingga dapat dengan mudah memasukkan jenis desain yang akan digunakan dan memasukkan nilai ketebalan ( $\mathrm{d}$ ) nilai konduktivitas $(\mathrm{k})$ dan menghitung nilai transmitannya.

Tabel 2. Nilai Transmitan dinding pasangan $1 / 2$ bata diplester kedua sisinya $2 \mathrm{~cm}$

\begin{tabular}{|l|c|c|c|c|c|}
\hline \multirow{2}{*}{ Desain Konstruksi Dinding } & Tebal & Konduktivitas & Resistan & Transmitan & Absorbsi \\
\cline { 2 - 4 } & $\mathbf{d}$ & $\mathbf{k}$ & $\mathbf{R}=\mathbf{d} / \mathbf{k}$ & $\mathbf{U}-$ Value = 1/R & $\boldsymbol{\alpha}$ \\
\cline { 2 - 4 } & $\mathbf{m}$ & $\mathbf{W} / \mathbf{m K}$ & $\mathbf{m}^{\mathbf{2}} \mathbf{K} / \mathbf{W}$ & $\mathbf{W} / \mathbf{m}^{\mathbf{2}} \mathbf{K}$ & \\
\hline 1. Permukaan luar & & & 0,050 & & \\
\hline 2. Plesteran 2 cm, dicat putih & 0,020 & 0,900 & 0,022 & & 0,300 \\
\hline 3. Batu bata tebal 10 cm (1/2 bata) & 0,100 & 0,890 & 0,112 & & 0,890 \\
\hline 4. Plesteran 2 cm & 0,020 & 0,900 & 0,022 & & \\
\hline 5. Permukaan dalam & & & 0,120 & & $\mathbf{0}$ \\
\hline & & & $\mathbf{0 , 3 2 7}$ & $\mathbf{3 , 0 6 0}$ & $\mathbf{0 , 2 6 7}$ \\
\hline
\end{tabular}

Sumber : Hasil olahan Peneliti 
Tabel 3. Nilai Transmitan dinding batako padat diplester kedua sisinya

\begin{tabular}{|l|c|c|c|c|c|}
\hline \multirow{2}{*}{ Desain Konstruksi Dinding } & Tebal & Konduktivitas & Resistan & Transmitan & Absorbsi \\
\cline { 2 - 5 } & $\mathbf{d}$ & $\mathbf{k}$ & $\mathbf{R = d} / \mathbf{k}$ & $\mathbf{U}-$ Value = 1/R & $\boldsymbol{\alpha}$ \\
\cline { 2 - 6 } & $\mathbf{m}$ & $\mathbf{W} / \mathbf{m K}$ & $\mathbf{m}^{\mathbf{2}} \mathbf{K} / \mathbf{W}$ & $\mathbf{W} / \mathbf{m}^{\mathbf{2}} \mathbf{K}$ & \\
\hline 1. Permukaan luar & & & 0,050 & & \\
\hline 2. Plesteran 2 cm putih agak mengkilap & 0,020 & 0,900 & 0,022 & & 0,300 \\
\hline 3. Batako padat t. 15 cm & 0,150 & 0,720 & 0,208 & & 0,860 \\
\hline 4. Plesteran 2 cm & 0,020 & 0,900 & 0,022 & & \\
\hline 5. Permukaan dalam & & & 0,120 & & $\mathbf{0 , 2 5 8}$ \\
\hline
\end{tabular}

Sumber : Hasil olahan Peneliti

Tabel 4. Nilai Transmitan dinding batako berlubang diplester kedua sisinya.

\begin{tabular}{|l|c|c|c|c|c|}
\hline \multirow{2}{*}{ Desain Konstruksi Dinding } & Tebal & Konduktivitas & Resistan & Transmitan & Absorbsi \\
\cline { 2 - 6 } & $\mathbf{d}$ & $\mathbf{k}$ & $\mathbf{R = d} / \mathbf{k}$ & $\mathbf{U}-$ Value = 1/R & $\boldsymbol{\alpha}$ \\
\cline { 2 - 6 } & $\mathbf{m}$ & $\mathbf{W} / \mathbf{m K}$ & $\mathbf{m}^{\mathbf{2}} \mathbf{K} / \mathbf{W}$ & $\mathbf{W} / \mathbf{m}^{\mathbf{2}} \mathbf{K}$ & \\
\hline 1. Permukaan luar & & & 0,050 & & \\
\hline 2. Plesteran 2 cm putih agak mengkilap & 0,020 & 0,900 & 0,022 & & 0,300 \\
\hline 3. Batako berlubang t 10 cm & 0,100 & 1,110 & 0,090 & & 0,860 \\
\hline 4. Plesteran 2 cm & 0,020 & 0,900 & 0,022 & & \\
\hline 5. Permukaan dalam & & & 0,120 & & $\mathbf{0 , 2 5 8}$ \\
\hline
\end{tabular}

Sumber : Hasil olahan Peneliti

Tabel 5. Nilai Transmitan dinding bata ringan diplester kedua sisinya

\begin{tabular}{|l|c|c|c|c|c|}
\hline \multirow{2}{*}{ Desain Konstruksi Dinding } & Tebal & Konduktivitas & Resistan & Transmitan & Absorbsi \\
\cline { 2 - 6 } & $\mathbf{d}$ & $\mathbf{k}$ & $\mathbf{R}=\mathbf{d} / \mathbf{k}$ & $\mathbf{U}-$ Value = 1/R & $\boldsymbol{\alpha}$ \\
\cline { 2 - 6 } & $\mathbf{m}$ & $\mathbf{W} / \mathbf{m K}$ & $\mathbf{m}^{\mathbf{2}} \mathbf{K} / \mathbf{W}$ & $\mathbf{W} / \mathbf{m}^{\mathbf{2}} \mathbf{K}$ & \\
\hline 1. Permukaan luar & & & 0,050 & & \\
\hline 2. Plesteran 2 cm putih agak mengkilap & 0,020 & 0,900 & 0,022 & & 0,300 \\
\hline 3. Bata ringan t 20 cm & 0,200 & 0,530 & 0,377 & & 0,860 \\
\hline 4. Plesteran 2 cm & 0,020 & 0,900 & 0,022 & & \\
\hline 5. Permukaan dalam & & & 0,120 & & $\mathbf{0 , 2 5 8}$ \\
\hline
\end{tabular}

Sumber : Hasil olahan Peneliti

Tabel 6. Nilai Transmitan dinding panel b-foam expanded polystyrene $12 \mathrm{~cm}$

\begin{tabular}{|l|c|c|c|c|c|}
\hline \multirow{2}{*}{ Desain Konstruksi Dinding } & Tebal & Konduktivitas & Resistan & Transmitan & Absorbsi \\
\cline { 2 - 6 } & $\mathbf{d}$ & $\mathbf{k}$ & $\mathbf{R = d} / \mathbf{k}$ & $\mathbf{U}-$ Value = 1/R & $\boldsymbol{\alpha}$ \\
\cline { 2 - 6 } & $\mathbf{m}$ & $\mathbf{W} / \mathbf{m K}$ & $\mathbf{m}^{\mathbf{2}} \mathbf{K} / \mathbf{W}$ & $\mathbf{W} / \mathbf{m}^{\mathbf{2}} \mathbf{K}$ & \\
\hline 1. Permukaan luar & & & 0,050 & & \\
\hline 2. Plesteran 2 cm putih agak meng & 0,020 & 0,900 & 0,022 & & 0,300 \\
\hline 3. Panel b-foam 12cm & 0,120 & 0,039 & 3,077 & & 0,860 \\
\hline 4. Plesteran 2 cm & 0,020 & 0,900 & 0,022 & & \\
\hline 5. Permukaan dalam & & & 0,120 & & $\mathbf{0 , 2 5 8}$ \\
\hline
\end{tabular}

Sumber : Hasil olahan Peneliti 
Tabel 7. Nilai Transmian dinding dengan material kayu tebal $1,3 \mathrm{~cm}$

\begin{tabular}{|l|c|c|c|c|c|}
\hline \multirow{3}{*}{ Desain Konstruksi Dinding } & Tebal & Konduktivitas & Resistan & Transmitan & Absorbsi \\
\cline { 2 - 6 } & $\mathbf{d}$ & $\mathbf{k}$ & $\mathbf{R}=\mathbf{d} / \mathbf{k}$ & $\mathbf{U}-$ Value = 1/R & $\boldsymbol{\alpha}$ \\
\cline { 2 - 6 } & $\mathbf{m}$ & $\mathbf{W} / \mathbf{m K}$ & $\mathbf{m}^{\mathbf{2}} \mathbf{K} / \mathbf{W}$ & $\mathbf{W} / \mathbf{m}^{\mathbf{2}} \mathbf{K}$ & \\
\hline 1. Permukaan luar & & & 0,050 & & \\
\hline 2. Kayu 1.3 cm & 0,013 & 0,150 & 0,087 & & \\
\hline 3. Permukaan dalam & & & 0,120 & \\
\hline
\end{tabular}

Sumber : Hasil olahan Peneliti

Tabel 8. Nilai Transmitan dinding dengan material kayu tebal $1,3 \mathrm{~cm}$ dibuat double dengan ruang udara $10 \mathrm{~cm}$

\begin{tabular}{|l|c|c|c|c|c|}
\hline \multirow{2}{*}{ Desain Konstruksi Dinding } & Tebal & Konduktivitas & Resistan & Transmitan & Absorbsi \\
\cline { 2 - 5 } & $\mathbf{d}$ & $\mathbf{k}$ & $\mathbf{R = d} / \mathbf{k}$ & $\mathbf{U}-$ Value = 1/R & $\boldsymbol{\alpha}$ \\
\hline 1. Permukaan luar & & $\mathbf{W} / \mathbf{m K}$ & $\mathbf{m}^{2} \mathbf{K} / \mathbf{W}$ & $\mathbf{W} / \mathbf{m}^{2} \mathbf{K}$ & \\
\hline 2. Kayu 1,3 cm & 0,013 & 0,150 & 0,087 & & \\
\hline 3. Ruang udara 10 cm & 0,100 & 0,103 & 0,971 & & $\mathbf{0 , 7 8 0}$ \\
\hline 4. Kayu 1,3 cm & 0,013 & 0,150 & 0,087 & & \\
\hline 5. Permukaan dalam & & & 0,120 & & \\
\hline & & & $\mathbf{1 , 3 1 4}$ & $\mathbf{0 , 7 6 1}$ & \\
\hline
\end{tabular}

Sumber : Hasil olahan Peneliti

Tabel 9. Nilai Transmitan kaca bening $3 \mathrm{~mm}$

\begin{tabular}{|l|c|c|c|c|c|}
\hline \multirow{3}{*}{ Desain Konstruksi Dinding } & Tebal & Konduktivitas & Resistan & Transmitan & Absorbsi \\
\cline { 2 - 6 } & $\mathbf{d}$ & $\mathbf{k}$ & $\mathbf{R = d} / \mathbf{k}$ & $\mathbf{U}-$ Value $=\mathbf{1} / \mathbf{R}$ & $\boldsymbol{\alpha}$ \\
\cline { 2 - 7 } & $\mathbf{m}$ & $\mathbf{W} / \mathbf{m K}$ & $\mathbf{m}^{\mathbf{2}} \mathbf{K} / \mathbf{W}$ & $\mathbf{W} / \mathbf{m}^{\mathbf{2} K}$ & \\
\hline 1. Permukaan luar & & & 0,050 & & \\
\hline 2. Kaca bening 3 mm & 0,003 & 0,900 & 0,003 & & $\mathbf{0 , 0 7 0}$ \\
\hline 3. Permukaan dalam & & & 0,120 & & \\
\hline & & & $\mathbf{0 , 1 7 3}$ & $\mathbf{5 , 7 6 9}$ & \\
\hline
\end{tabular}

Sumber : Hasil olahan Peneliti

Tabel 10. Nilai Transmitan kaca bening $3 \mathrm{~mm}$ dibuat double dengan ruang udara $6,4 \mathrm{~mm}$ tanpa aluminium thermal break

\begin{tabular}{|c|c|c|c|c|c|}
\hline \multirow{3}{*}{ Desain Konstruksi Dinding } & Tebal & Konduktivitas & Resistan & Transmitan & Absorbsi \\
\hline & d & $\mathbf{k}$ & $\mathbf{R}=\mathbf{d} / \mathbf{k}$ & U-Value $=\mathbf{1} / \mathbf{R}$ & $\alpha$ \\
\hline & $\mathbf{m}$ & $\mathbf{W} / \mathbf{m K}$ & $\mathbf{m}^{2} \mathbf{K} / \mathbf{W}$ & $\mathbf{W} / \mathbf{m}^{2} \mathbf{K}$ & \\
\hline 1. Permukaan luar & & & 0,050 & & \\
\hline 2. Double Glazing $3 \mathrm{~mm}$ bening & 0,0124 & 0,147 & 0,084 & & 0,300 \\
\hline \multicolumn{6}{|l|}{$6.4 \mathrm{~mm}$ air space } \\
\hline \multicolumn{6}{|l|}{ aluminium without thermal } \\
\hline \multicolumn{6}{|l|}{ break } \\
\hline 3. Permukaan dalam & & & 0,120 & & \\
\hline & & & 0,254 & 3,936 & \\
\hline
\end{tabular}

Sumber : Hasil olahan Peneliti

Dasar pertimbangan dalam memilih desain dinding untuk bangunan hemat energi adalah yang memiliki nilai transmitan yang kecil, namun perlu dipertimbangkan juga segi efisiensi dan efektifitasnya. Bila menggunakan cladding, sebaiknya menggunakan warna terang, bila 
menggunakan warna gelap bisa memperbesar penyerapan panas pada bangunan, desain selubung dengan ruang udara memiliki perbedaan yang signifikan dibanding dengan yang tidak diberi ruang udara. Semakin tebal ruang udara menghasilkan nilai transmitan yang lebih kecil. Dengan dasar ini kita bisa memilih desain seperti apa yang paling tepat/yang paling efektif dan efisien untuk penggunaan Cladding pada selubung bangunan..

Bila menggunakan kaca :

a. Kaca bening. Semakin tebal kaca, semakin baik menahan panas

b. Penggunaan kaca warna lebih baik daripada kaca bening. Semakin tebal kaca semakin baik.

c. Penggunaan kaca coating lebih baik daripada kaca warna.

d. Untuk memperbaiki kualitas kaca dapat juga digunakan kaca film untuk melapisi kaca yang dapat menolak radiasi matahari. Penggunaan kaca film sesuaikan dengan kebutuhan fungsi ruang. Gunakan yang dapat menolak panas.Saat ini terdapat jenis kaca film yang dapat menolak panas dengan spesifikasi yang dapat disesuaikan dengan kebutuhan yaitu kaca film jenis VKOOL

Tabel 11. Spesifikasi Jenis Kaca Film V-Kool

\begin{tabular}{lcccccccc}
\hline \multicolumn{1}{c}{ Perfomance Data } & VK & VK & V-K & V-K & V-K & V-K & V-K & V-K \\
& Ique & Ique & 70 & 40 & 55 & VIP & X 05 & X 15 \\
\hline $\begin{array}{l}\text { Aplikasi Tingkat } \\
\text { Kegelapan }\end{array}$ & $20 \%$ & $30 \%$ & $20 \%$ & $40 \%$ & $30 \%$ & $60 \%$ & $80 \%$ & $60 \%$ \\
Visible Light & $70 \%$ & $53 \%$ & $70 \%$ & $43 \%$ & $57,8 \%$ & $15,06 \%$ & $6,46 \%$ & $17 \%$ \\
Transmission & $8 \%$ & $7 \%$ & $8 \%$ & $10 \%$ & $8,6 \%$ & $18,82 \%$ & $14 \%$ & $12 \%$ \\
Visible Light & $99,98 \%$ & $99,98 \%$ & $99 \%$ & $99 \%$ & $99 \%$ & $99,98 \%$ & $99 \%$ & $99 \%$ \\
$\begin{array}{l}\text { Reflectance } \\
\text { Ultra-violet Rejection }\end{array}$ & $96 \%$ & $94 \%$ & $94 \%$ & $98 \%$ & $97,7 \%$ & $96,73 \%$ & $87 \%$ & $87 \%$ \\
$\begin{array}{l}\text { Infra-red Rejection } \\
\text { Shading Coefficient }\end{array}$ & 0,50 & 0,45 & 0,50 & 0,42 & 0,48 & 0,323 & 0,351 & 0,36 \\
$\begin{array}{l}\text { Total Solar Energy } \\
\text { Rejection }\end{array}$ & $55 \%$ & $61 \%$ & $55 \%$ & $65 \%$ & $59,6 \%$ & $73,42 \%$ & $71,04 \%$ & $69 \%$ \\
\hline
\end{tabular}

(Sumber : www.vkool-indonesia.com/product)

Bisa dilihat pada perbandingan penerapan desain konstruksi bangunan untuk mengurangi beban energi bangunan pada penggunaan AC dengan menghitung beban panas dalam ruang.

Sebuah ruangan pada sebuah gedung sudah diketahui :

Ukuran ruang panjang $10 \mathrm{~m}$ ( yang berhubungan dengan luar), lebar $4 \mathrm{~m}$ dan tinggi $3 \mathrm{~m}$. Dinding dari batu bata setebal $10 \mathrm{~cm}$ diplester kedua sisinya nilai $\mathrm{U}=3,06 \mathrm{~W} / \mathrm{m}^{2} \mathrm{~K}$ dicat warna putih. Absorbsi bata merah $=0,89$ absorbsi cat putih 0,30 . Kaca polos tebal $5 \mathrm{~mm}$ lebar $7 \mathrm{~m}$ tinggi $2 \mathrm{~m}$.

Konstruksi dinding pasangan $1 / 2$ bata diplester kedua sisi

Luas bidang dinding $\left(\mathrm{A}_{\text {dinding }}\right)=16 \mathrm{~m}^{2}$ (yang berhubungan dengan luar menghadap barat laut)

Luas bidang kaca $\left(\mathrm{A}_{\text {kaca }}\right)=14 \mathrm{~m}^{2}$

Perbedaan suhu luar dan dalam pada dinding $\left(\Delta \mathrm{T}_{\text {dinding }}\right)=10^{\circ} \mathrm{C}$

Perbedaan suhu luar dan dalam pada kaca $\left(\Delta \mathrm{T}_{\text {kaca }}\right)=8^{\circ} \mathrm{C}$

Qi $($ Panas internal $)=2000 \mathrm{~W}$, Qs $($ panas matahari yang menembus kaca $)=2500 \mathrm{~W}$,

$\mathrm{Qv}($ Panas dari ventilasi $)=0 \mathrm{~W}$,

Qc ( Panas melalui dinding dan panas melalui kaca) :

$\mathrm{Qc}=\mathrm{A}_{\text {dinding }} \cdot \mathrm{U}_{\text {dinding }} \cdot \Delta \mathrm{T}_{\text {dinding }}+\mathrm{A}_{\text {kaca }} \cdot \mathrm{U}_{\text {kaca }} \cdot \Delta \mathrm{T}_{\mathrm{kaca}}=1128 \mathrm{~W}$

Beban Penyejukan : ( berdasar keseimbangan termal)

$\mathrm{Q}_{\mathrm{m}}=\mathrm{Q}_{\mathrm{i}}+\mathrm{Q}_{\mathrm{s}}+\mathrm{Q}_{\mathrm{c}}+\mathrm{Q}_{\mathrm{v}}=5,628 \mathrm{~kW}$

Nilai OTTV

$$
=19200 \mathrm{Btu}=2,1 \mathrm{PK}(1 \mathrm{PK}=9000 \mathrm{Btu})
$$

$$
\text { OTTV }=\alpha\left[\mathrm{U}_{\mathrm{w}} \mathrm{x}(1-\mathrm{WWR}) \mathrm{xTD_{ \textrm {Ek } }}\right]+\left(\mathrm{U}_{\mathrm{f}} \mathrm{xWWRx} \Delta \mathrm{T}\right)+(\mathrm{SCxWWRxSF})=109,3 \mathrm{~W} / \mathrm{m}^{2}
$$

Bandingkan dengan Desain dinding berikut :

Ukuran ruang panjang $10 \mathrm{~m}$ ( yang berhubungan dengan luar), lebar $4 \mathrm{~m}$ dan tinggi $3 \mathrm{~m}$. Dinding dari bata ringan setebal $20 \mathrm{~cm}$ diplester kedua sisinya nilai $\mathrm{U}=1,690 \mathrm{~W} / \mathrm{m}^{2} \mathrm{~K}$ dicat warna putih. 
Absorbsi bata ringan $=0,89$ absorbsi cat putih 0,30 . Kaca bening $3 \mathrm{~mm}$ dilapisi kaca film jenis V-Kool Ique73FG ukuran lebar $7 \mathrm{~m}$ tinggi $2 \mathrm{~m}$

Luas bidang dinding $\left(\mathrm{A}_{\text {dinding }}\right)=16 \mathrm{~m}^{2}$ ( berhubungan dengan luar menghadap barat laut)

Luas bidang kaca $\left(\mathrm{A}_{\text {kaca }}\right)=14 \mathrm{~m}^{2}$

Perbedaan suhu luar dan dalam pada dinding $\left(\Delta \mathrm{T}_{\text {dinding }}\right)=10^{\circ} \mathrm{C}$

Perbedaan suhu luar dan dalam pada kaca $\left(\Delta \mathrm{T}_{\text {kaca }}\right)=8^{\circ} \mathrm{C}$

Qi $($ Panas internal $)=2000 \mathrm{~W}, \mathrm{Qv}($ Panas dari ventilasi $)=0 \mathrm{~W}$,

Tabel 12. Nilai Transmitan kaca bening 3 mm dilapisi kaca Film V-Ko01 Ique73FG

\begin{tabular}{|l|c|c|c|c|c|}
\hline \multirow{3}{*}{ Desain Konstruksi Dinding } & Tebal & Konduktivitas & Resistan & Transmitan & Absorbsi \\
\cline { 2 - 6 } & $\mathbf{d}$ & $\mathbf{k}$ & $\mathbf{R = d} / \mathbf{k}$ & $\mathbf{U}-$ Value = 1/R & $\boldsymbol{\alpha}$ \\
\cline { 2 - 6 } & $\mathbf{m}$ & $\mathbf{W} / \mathbf{m K}$ & $\mathbf{m}^{\mathbf{2}} \mathbf{K} / \mathbf{W}$ & $\mathbf{W} / \mathbf{m}^{\mathbf{2}} \mathbf{K}$ & \\
\hline 1. Permukaan luar & & & & & \\
\hline 2. Kaca Film V-Kool Ique73FG & & & 0,050 & & $\mathbf{0 , 6 9 0}$ \\
\hline 2. Kaca bening 3 mm & 0,003 & 0,900 & 0,003 & & \\
\hline 3. Permukaan dalam & & & 0,120 & & \\
\hline & & & $\mathbf{1 , 1 3 3}$ & $\mathbf{0 , 8 8 2}$ & \\
\hline
\end{tabular}

Sumber : Hasil olahan Peneliti

Kualitas kaca diperbaiki dengan penambahan kaca film V-Kool Ique73FG yang memiliki kemampuan menolak total energi matahari 55\% sehingga Intensitas radiasi matahari menjadi $79,7 \mathrm{~W} / \mathrm{m}^{2}$ (SHGF 0,70 Intensitas radiasi matahari menjadi $177 \mathrm{~W} / \mathrm{m}^{2} \times 45 \%=79,7 \mathrm{~W} / \mathrm{m}^{2}$ ), Shading Coefficient 0,5 U-Value 0,882 sehingga

Qs $=\mathrm{A}_{\text {kaca }} \times \mathrm{SHGF} \times \mathrm{SC}=557,9 \mathrm{~W}$

Qc ( Panas melalui dinding dan panas melalui kaca) :

$\mathrm{Qc}=\mathrm{A}_{\text {dinding }} \cdot \mathrm{U}_{\text {dinding }} \cdot \Delta \mathrm{T}_{\text {dinding }}+\mathrm{A}_{\text {kaca }} \cdot \mathrm{U}_{\text {kaca }} \cdot \Delta \mathrm{T}_{\text {kaca }}=369,184 \mathrm{~W}$

Beban Penyejukan : $\mathrm{Q}_{\mathrm{m}}=\mathrm{Q}_{\mathrm{i}}+\mathrm{Q}_{\mathrm{s}}+\mathrm{Q}_{\mathrm{c}}+\mathrm{Q}_{\mathrm{v}}$ $=2,927084 \mathrm{~kW}=10035,71 \mathrm{Btu}=1,1151 \mathrm{PK}(1 \mathrm{PK}=9000 \mathrm{Btu})$

OTTV $=\alpha\left[\mathrm{U}_{\mathrm{w}} \mathrm{x}(1-\mathrm{WWR}) \mathrm{xTD_{ \textrm {Ek } }}\right]+\left(\mathrm{U}_{\mathrm{f}} \mathrm{XWWR} \Delta \mathrm{T}\right)+(\mathrm{SCxWWRxSF})=24,573 \mathrm{~W} / \mathrm{m}^{2}$

Dari perbandingan di atas dapat diketahui bahwa pemilihan desain selubung bangunan yang baik dapat membuat bangunan menjadi hemat energi dan sangat ditentukan oleh nilai transmitan ( U-Value) desain konstruksinya.

Pada Penelitian ini untuk memudahkan para Perancang, maka dibuat Tabel Perhitungan Perpindahan Panas atau nilai Transmitan (U-Value), dimana tinggal dimasukkan detail desain konstruksi dinding yang diinginkan yaitu ketebalan, nilai konduktivitas material, nilai resistan udara permukaaan ( luar dan dalam) sehingga didapat nilai Resistan dari masing-masing bahan, nilai Total Resistan, dan nilai Transmitan dari desain konstruksi yang diinginkan.

5

KESIMPULAN

Penggunaan energi terbesar dalam bangunan adalah pada proses kerja sistem pengkondisian udara, yang besarnya sangat tergantung pada jumlah panas eksternal yang masuk melalui selubung bangunan dan menjadi beban panas internal, besarnya sangat ditentukan oleh nilai transmitan dari desain selubung bangunan. Semakin besar nilai transmitan, semakin besar beban panas internal, artinya energi yang digunakan pada proses pengkondisian udara untuk mencapai suhu sesuai kenyamanan termal yang dikondisikan menjadi semakin besar, beban panas internal inilah yang harus dikurangi untuk menghasilkan bangunan hemat energi. Pengurangan beban panas internal dapat dilakukan dengan pemilihan desain selubung bangunan yang memiliki nilai transmitan yang kecil sehingga panas sedikit mungkin masuk kedalam bangunan (Bradshaw,1993:54-56), untuk itu pilihlah bahan/material yang memiliki nilai konduktivitas yang kecil dan buatlah desain konstruksi dinding dengan nilai resistan yang besar sehingga nilai transmitannya menjadi kecil. Untuk memudahkan, maka pada penelitian ini 
dibuat Tabel Perhitungan Nilai Transmitan (U-Value), sehingga data yang dimasukkan adalah detail desain konstruksi dinding yang diinginkan yaitu ketebalan, nilai konduktivitas material, nilai resistan udara permukaaan ( luar dan dalam) sehingga didapat nilai Resistan dari masingmasing bahan, nilai Total Resistan, dan nilai Transmitan dari desain konstruksi yang diinginkan.

\section{SARAN}

Untuk menyempurnyakan penelitian ini dibutuhkan adanya penelitian lanjutan tentang selubung bangunan hemat energi yang difokuskan pada desain konstruksi atap bangunan.

\section{DAFTAR PUSTAKA}

Arismunandar dan Saito, (1995), Penyegaran Udara, Cetakan kelima, PT. Pradnya Paramita, Jakarta.

ASHRAE (American Society of Heating, Refrigeration, and Air Conditioning Engineers) Handbook Committee, (2001), ASHRAE Fundamental HandBooks- 2001, ASHRAE 1791 Tullie Circle, Atlanta.

Badan Standarisasi Nasional, (2001), Tata Cara Perancangan Sistem Ventilasi Dan Pengkondisian Udara Pada Bangunan Gedung. SNI 03-6572-2001, Badan Standarisasi Nasional Indonesia, Jakarta.

Badan Standarisasi Nasional, (2011), Konservasi Energi Selubung Bangunan pada Bangunan Gedung, SNI 6389:2011, Badan Standarisasi Nasional Indonesia, Jakarta.

Badan Standarisasi Nasional (2011), Konservasi Energi Sistem Tata Udara pada Bangunan Gedung, SNI 03-6390-2011, Badan Standarisasi Nasional Indonesia, Jakarta.

Bradshaw V (1993), Building Control System, Second edition, John wiley \& Sons,Inc, New York.

Dewan Energi Nasional Republik Indonesia, (2019), Outlook Energi Indonesia 2019, Kementerian Energi dan Sumber Daya Mineral, Jakarta.

Frick, Ardiyanto, dan Darmawan, (2008), Ilmu Fisika Bangunan. Kanisius, Yogyakarta.

Insulasi Polyurethane, http://www.antipanas.blogspot.co.id/, (2016).

Kaca Film V-Kool untuk Bangunan, http://www.vkool-indonesia.com/bangunan/portfolio, (2017).

Kementerian Energi dan Sumber Daya Mineral, (2012), Pedoman Energi Efisiensi untuk Desain Bangunan Gedung Indonesia, Edisi Pertama, Jakarta.

Lovell J, (2010), Building Envelope an Integrated Approach, Princeton Architectural Press, New York.

Mediastika Ch, (2013), Hemat Energi dan Lestari Lingkungan Melalui Bangunan, Edisi 1, Andi, Yogyakarta.

Panel Polystyrene,

info@b-panel.com/dan www.b-foam.com/, (2016)

Palm J, (2010), Energy Efficiency, Sciyo, Croatia.

Polister Hilon Insulation,

http://www.hiloninsulation.semarangpromo.com/, (2016).

Prakoso, Lamahala, dan Sentanu, (2014), Kajian Penerapan Material Pada Selubung Bangunan Yang Mempengaruhi Kenyamanan Termal dan Visual, Jurnal Reka karsa Volume 2 Nomor 2, Jurusan Teknik Arsitektur Itenas.

Sala M, (1998), Architecture: Comfort and Energy, Elsevier, Amsterdam.

Satwiko, (2009), Fisika Bangunan, Andi, Yogyakarta.

Szokolay S. V, (1980), Environmental Science Handbook for Architects and Builders, The Construction Press, New York. 